\title{
The Operating Patterns of Learner Emotions in Second Language Learning
}

\author{
Huanhuan Ren ${ }^{1}$, Chi $\mathrm{Ma}^{2}$ \\ ${ }^{1}$ Teaching and Research Institute of Foreign Languages Bohai University Jinzhou, Liaoning Province, China \\ ${ }^{2}$ Jinzhou Institute of Forestry Research Jinzhou Forestry Bureau Jinzhou, Liaoning Province, China \\ \{renhuanhuan2014\}@163.com, machi2014@tom.com
}

\begin{abstract}
Learner emotions play a decisive role in promoting second language learning and have increasingly attracted the attention of scholars both at home and abroad. The emotional education in China is still stuck in the "emotion as a tool" stage, and has not yet become a "substantial presence". Based on discussions on various definitions, benefits and development review of emotion in second language learning, two forms of operating patterns of affective factors are found in language pedagogy, which are emotions affecting learning and affecting emotions in learning, and the utilization of the two operating patterns are ultimately conductive to optimizing cognitive effects and enhancing students' emotional intelligence.
\end{abstract}

Index Terms - Learner emotions, Operating patterns, Second language learning

\section{Introduction}

There are various phenomena that cannot be ignored when one questions the impacts of affective factors on students' second language learning. Any underestimate of emotions of learners throughout the learning process will ultimately lead to emotional illiteracy, emotional deficiency and even emotional hunger. Besides, without the participation of affective processes in learning, the effectiveness of cognitive acquisition in second language is not guaranteed. In view of this, affective factors and cognitive factors should not function independently or exclusively in any educational settings. We will argue for how instructors in language teaching could activate emotions of learners in second language learning, and thus to foster both cognitive capacities and emotional competencies of learners. This article is a summary of this research work, which hopefully providing a useful reference for future second language classroom practice.

\section{The Holistic Review of Emotion}

\section{A. The Definition of Emotion}

What is an emotion? As Fehr and Russell observed, "everyone knows what an emotion is, until asked to give a definition [1]". Emotion researchers within the affective sciences appear to be converging on a high-level definition of emotion, and various perspectives in the study of emotional meanings were offered in an attempt to characterize emotional meaning. Russell believes that emotions arise from cognitive interpretations of core physiological activities ${ }^{[2]}$. From the view of psychology, emotion is the attitude of people obtained when experiencing the objective reality, indicating whether objective reality meets the individual's needs [3]. Philosophically, emotion is considered as the subjective reflection of value relation between human subjects and material objects. From the above, we can see emotions are complex phenomena and rich in content, and the main characteristics of emotions, as scholars observe, are richness, heterogeneity, vagueness and openness for multiple interpretations.

\section{B. Benefits to Learners}

Emotions affect students' developments from many aspects. Benefits of emotions are not limited to raising cognitive level of learners, but also promoting other qualities of individual learners. Previous brain science researches have shown that emotions arouse excitement of the right brain, and cognitions stimulate the excitement of the left brain. Wholebrain learning can be achieved by improving the coordination of the two hemispheres of a brain ${ }^{[4]}$. And also as Gross stresses, learning can be enlivened and strengthened by activating more of the brain's potential and students can accelerate and enrich learning, by engaging the senses, emotions, imagination [5]. Actually the emotional evolution coming to the surface and having been gaining momentum, begins with the researches of Daniel Goleman, professor of psychology at Harvard University, whose theories completely subvert the mainstream IQ-dominant view of life success. Goleman stresses that IQ contributes only about $20 \%$ to success in life, the rest $80 \%$ of success depends on EQ ${ }^{[6]}$. Affective competence plays a decisive role in personal success at work, personal mental health, happy life and so forth. In other words, emotional intelligence is crucial abilities for any living person in the world.

\section{Emotional Education}

In the 1950s, American educational psychologist Benjamin S. Bloom and other scholars regard affective competence as one of the three educational objectives with knowledge-based goal and skills-based goal as the other two ${ }^{[7]}$. Affective objectives typically target the awareness and growth in attitudes, emotion, and feelings of learners. This affective domain is further divided into several categories or levels of expertise, which are receiving, responding, valuing, organization and characterization by a value or value complex. Recently, scholars from more than 10 countries including Europe and the United States in the International Symposium 
on Emotional Education held by Volcker University, agrees to the following definition of emotional education: emotional education is part of school education, which focuses on students' attitude, emotions, feelings and beliefs, and students' individual development and social development as well as their self-esteem should be included in emotional education ${ }^{[8]}$. More importantly, emotional education transcends individual students and emphasizes the relationship among students, and interpersonal and social skills are the core of emotional education.

\section{Emotion as an Incentive Factor in Second Language Learning (SLL)}

\section{A. The Linguistic View}

When referring to the field of language learning, Apelt and Koernig offered the definition as: affect is the totality of all components of foreign-language instruction that influences the emotional attitude towards learning a foreign language and towards using it, as well as the foreign language atmosphere in general and the success of the learning and teaching process in particular [9]. However, Arnold and Brown propose that emotion in language can be viewed from two perspectives ${ }^{[10]}$. One focuses on the language learner as individual, including self-confidence, motivation, anxiety, inhibition, etc. The other is concerned with the learner as a participant in a socio-cultural situation, an individual who necessarily relates to others, including classroom transaction, empathy and so on. The above interpretations of emotion provide language researchers with clear vision of what domains emotion covers in this specific filed and what aspects might be concentrated on for developing positive emotions.

\section{B. Current Developments}

The concept of emotion in second language learning has a long history, and teachers in this field have achieved a large number of insightful results. In late 1970s, teaching methods in second language pedagogy such as suggestopedia, the silent way, community language learning, total physical response, and natural approach have highlighted affective factors in SLL ${ }^{[11]}$. With the focus of language teaching and research shifted from "teacher-centre" to "student-centre" since the 1980s, emotion has been mentioned again and is regarded as a critical factor in second language learning. Since then foreign scholars have carried out a series of related research on affective factors in language teaching. In fact, emotional education in China begins from the 1990s and the research on learners' emotions has been highly considered by domestic scholars and educators. But the emotional education in China is still stuck in the "emotion as a tool" stage, and has not yet become a "substantial presence". Its main purpose is limited to "connecting cognitions and deepening moral education ${ }^{[12],}$,

\section{Emotional Factors in SLL}

Over the past decades, Chinese language scholars have just paid main attentions to training students' cognitional ability but neglected the function of affective factors influenced during the teaching and learning process. Language educators should recognize the critical role of emotions in language education. The relationship between cognitive development and affective development are not separate, independent and exclusive, and the two aspects of learner development should be put into use by instructors to achieve complementary and mutually reinforcing effect, thus to resolve various affective problems in domestic educational settings. It's worth noticing that the execution of affective language teaching strategies in classroom should not be random but rule-based, and major emotional sources, such as learning materials, study peers, tutors and learning environment are open to be explored in second language teaching. Once those emotional sources have been activated, a rich emotional experience will be formed through students.

\section{The Operating Patterns of Emotions in Second Language Pedagogy}

\section{A. Emotions Affect Learning}

Learner emotions are regarded as a tool of teaching to promote students' cognitive competencies. Above all, instructors are encouraged to involve students in making full use of learning materials, which are not ordinary objects, but personalized things, containing a lot of emotional factors. Especially, students can gain an insight into emotional factors expressed explicitly or implicitly in second language materials, which is much easier than learning materials full of equations and data. Multimedia tools should be put into use to help students effectively complete language learning tasks through video, audio, pictures and so forth. By involving students' emotions in language learning materials, students' interests are triggered and students' attention is actively engaged in the whole process of learning.

Moreover, students ought to be provided with opportunities to collaborate with peer students in the classroom and outside the classroom. It requires teachers to design cooperative learning tasks for students and the tasks should be close to the real situation and highly related to learners' emotional needs. With positive emotions engaged into language tasks, the construction of knowledge can take place and the cognitive level of learners is improved and fostered. Besides, peer assessment should be carried out afterwards to assess the students' accomplishments and integrate learner emotions into students' learning needs.

A positive emotion towards learning environment is conducive to students' learning. Only students love the environment, can the learning taking place in that environment makes sense. First, learning environment should be kept clean and comfortable, such as tables and chairs aren't damaged and are placed in a way that is good for student exchanges, the temperature is neither too cold nor too hot, and the room is far away from the toilet and so forth. Second, teaching equipments in the classroom should not block the sight of students and students in the corner of the classroom can see 
the learning contents in blackboard or PPT clearly. Lastly, cultural atmosphere is needed in the classroom. Students are allowed to be themselves in the process of learning and the classroom is a place where students can take risks, develop confidence and grow academically and emotionally.

\section{B. Affecting Emotions in Learning}

Learner emotions are regarded as an objective of teaching to promote students' emotional competencies. Language learning shouldn't be confined to language proficiency, emotional attainments behind language materials are no less important than language itself. Both linguistic and emotional content of learning materials should be explored by students, so that cultural awareness and cultural knowledge of learners are fostered. Language materials seem to be a platform rich in resources including politics, economics, science, technology, literature, business, arts, etc., and are beneficial to the development of learners' emotional qualities, such as attitudes change, the ability to appreciate, the formation of noble sentiments and so forth.

Students' emotional intelligence is highly affected by group activities, in which students feel their emotions, express their emotions, control their emotions, recognize others' feelings and influence others' emotions. During this process, the information of respect and kindness is conveyed to each other, recognition and understanding is obtained by other people, feelings and emotions are shared, emphasis is not placed on oneself and full concern is given to the understanding of other people. Through meaningful interaction and cooperation with other people in learning settings, students can gain positive emotional experiences, achieve personal self-exploration, and acquire a high level of emotional intelligence including friendships, interpersonal skills, teamwork spirit, etc.

Instructors should respond effectively and timely to solve emotional problems of students arising in the learning settings. On the one hand, learners should be treated equally and fairly by teachers. It requires teachers to respect individual differences in cognitive ability and learning style, keep a watchful eye on psychological characteristics of students, and take care of different feelings of each individual learner, thus to ensure that students are involved in learning activities both behaviourally and emotionally. On the other hand, teachers should love students from the bottom of heart, and would like to be a help for learners at any time and in any aspect, for example, helping students hold a positive life attitude and so forth. Instead of learning outcomes, teachers' emphasis should be given to students' learning processes, ultimately to promote students' positive emotional experiences and enhance learners' emotional competencies.

\section{Conclusion}

Leaner emotions play a decisive role in second language learning, and its far-reaching and influential effect has become a big concern in educational field. Affective education is an indivisible part of whole education, and instructors should pay special attention to various emotions of learners. It's suggested that language educators should keep a watchful eye on the two forms of operating patterns of affective factors taking place in language pedagogy, which are emotions affecting learning and affecting emotions in learning. Emphasis of instructors should be placed on combining the two aspects together and engaging affective factors into specific teaching approaches, ultimately to promote students' cognitive and emotional attainments.

\section{Acknowledgment}

This research was supported by Jinzhou (China) Social Science Key Research Project (Y2014:288) and Jinzhou (China) Social Science Key Research Project (Y2014:320).

\section{References}

[1] B. Fehr, J. A. Russell, "Concept of emotion viewed from a prototype perspective," Journal of Experimental Psychology, vol. 113, pp. 464$486,1984$.

[2] J. Russell, "Core affect and the psychological construction of emotion," Psychological Review, vol. 110, pp. 145-172, 2003.

[3] Z. X. Zhu, The Dictionary of Industrial Psychology, Beijing: Beijing Normal University Press, 1989.

[4] X. Yu, Emotional Education, Beijing: Science and Education Press, 2002.

[5] R. Gross, "Lifelong learning in the learning society of the twenty-first century”, in C. Collins, J. Mangieri (eds.) Teaching Thinking: an Agenda for the Twenty-First Century, New York: Lawrence Erlbaum, 1992.

[6] D. Goleman, Emotional Intelligence, Shanghai: Shanghai Scientific and Technical Publishers, 1997.

[7] D. R. Krathwohl, B. S. Bloom and B.B. Masia, Taxonomy of Educational Objectives: Affective Domain, David McKay Company, Inc, 1964.

[8] P. Lang, "Affective education - an international perspective," Journal of East China Normal University (Educational Sciences), vol. 3, pp. 25-36, 1995.

[9] W. Apelt, H. Koering, "Affectivity in the teaching of foreign language," European Education, vol. 29, pp. 29-46, 1997.

[10]J. Arnold, Affect in Language Learning, New York: Cambridge University Press, 1999.

[11]H.P. Cui, "The design of emotional instruction in network education," China Educational Technology, vol. 1, pp. 59-62, 2006.

[12]X. Zhao, "A review of progress and trend of foreign research on emotional education," Comparative Education Review, vol. 8, pp. 54-59, 2013. 